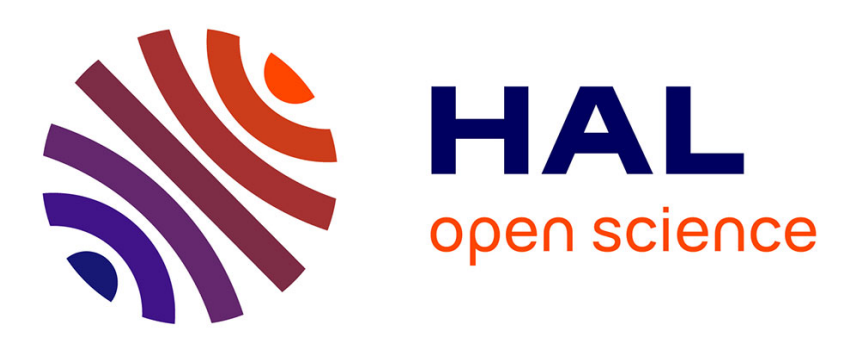

\title{
The effect of neighbourhood income and deprivation on pregnancy outcomes in Amsterdam, the Netherlands
}

C Agyemang, T.G.M. Vrijkotte, M. Droomers, M.F van Der Wal, G.J. Bonsel, K Stronks

\section{- To cite this version:}

C Agyemang, T.G.M. Vrijkotte, M. Droomers, M.F van Der Wal, G.J. Bonsel, et al.. The effect of neighbourhood income and deprivation on pregnancy outcomes in Amsterdam, the Netherlands. Journal of Epidemiology and Community Health, 2009, 63 (9), pp.755-n/a. 10.1136/jech.2008.080408 . hal-00477869

\section{HAL Id: hal-00477869 \\ https://hal.science/hal-00477869}

Submitted on 30 Apr 2010

HAL is a multi-disciplinary open access archive for the deposit and dissemination of scientific research documents, whether they are published or not. The documents may come from teaching and research institutions in France or abroad, or from public or private research centers.
L'archive ouverte pluridisciplinaire HAL, est destinée au dépôt et à la diffusion de documents scientifiques de niveau recherche, publiés ou non, émanant des établissements d'enseignement et de recherche français ou étrangers, des laboratoires publics ou privés. 


\title{
The effect of neighbourhood income and deprivation on pregnancy outcomes in Amsterdam, the Netherlands
}

\author{
C. Agyemang $\mathbf{P h D}{ }^{1, *}$ \\ T.G.M. Vrijkotte $\mathbf{P h D}^{1}$ \\ M. Droomers $\mathbf{P h D}^{2}$ \\ M.F van der Wal PhD $^{3}$ \\ G.J. Bonsel PhD ${ }^{4}$ \\ K. Stronks PhD ${ }^{1}$
}

1. Department of Social Medicine, Academic Medical Centre, University of Amsterdam, The Netherlands

2. Centre for Prevention and Health Services Research; National Institute for Public Health and the Environment, PO Box 1, 3720 BA Bilthoven, The Netherlands

3. Municipal Health Service, Department of Epidemiology, Documentation and Health Promotion, Amsterdam, The Netherlands.

4. Institute of Health Policy and Management, Erasmus MC Rotterdam, Rotterdam, The Netherlands.

Word count: 2875

"the Corresponding Author has the right to grant on behalf of all authors and does grant on behalf of all authors, an exclusive licence (or non exclusive for government employees) on a worldwide basis to the BMJ Publishing Group Ltd and its Licensees to permit this article (if accepted) to be published in JECH and any other BMJPGL products to exploit all subsidiary rights, as set out in our licence (http://jech.bmj.com/ifora/licence.pdf)."

${ }^{*}$ Correspondence to: Dr Charles Agyemang, Dept. of Social Medicine, Academic Medical Centre, University of Amsterdam, Meibergdreef 9, 1105 AZ Amsterdam, The Netherlands, Tel: 003120 5664885, Fax: 0031206972316

Email: c.o.agyemang @amc.uva.nl 


\section{ABSTRACT}

Background: Studies suggest that the neighbourhoods in which people live influence their health. The main objective of this study was to investigate the associations of neighbourhoodlevel income and unemployment/social security benefit on pregnancy outcomes: preterm delivery, small for gestational age (SGA), pregnancy induced hypertension (PIH) and miscarriage/perinatal death in Amsterdam, the Netherlands.

Methods: A random sample of 7883 from 82 neighbourhoods in Amsterdam. Individuallevel data from the Amsterdam Born Children and their Development (ABCD) study were linked to data on neighbourhood-level factors. Multilevel logistic regression was used to estimate odds ratios and neighbourhood-level variance.

Results: After adjustment for individual-level factors (age, parity, education, ethnicity, smoking and obesity), women living in low income neighbourhoods (third, second and first quartiles) were more likely than women living in high income neighbourhoods (fourth quartile) to have SGA births: odds ratios were 1.32 (95\% CI: 1.04-1.68), 1.42 (1.11-1.82) and $1.62(1.25-2.08)$ respectively. Women living in the quartile of neighbourhoods with the highest unemployment/social security benefit were more likely than those living in the quartile with the lowest unemployment/social security benefit to have SGA births 1.36 (1.081.72). The neighbourhood-level variance was significant only for SGA births. No significant associations were found between neighbourhood-level factors and other pregnancy outcomes. Conclusion: Our findings suggest that neighbourhood income and deprivation are related to SGA births. More research is needed to explore possible mechanisms underlying poor neighbourhood environment and pregnancy outcomes, in particular through stress mechanisms. Such information might be necessary to help improve maternal and foetal health.

Keywords: Preterm birth; small for gestational age; pregnancy induced hypertension; neighbourhood deprivation; the Netherlands 


\section{INTRODUCTION}

Growing attention is being paid to the impact of residential neighbourhood environment on health outcomes. A large body of literature,[1-6] suggests that the neighbourhood in which people live influences their health, although a few studies failed to confirm this.[7-9] Neighbourhood socio-economic status (SES) and deprivation, for example, have been shown to be strongly related to several poor health outcomes.[1] It has been proposed that health inequalities are the result of different accumulation of exposures and experiences that have their roots in the material world.[10-12] The effects of socio-economic inequalities on health are the consequence of a combination of negative exposures and a lack of individual economic resources associated with a systematic low investment in a whole series of human, physical, health and social infrastructure.[10] The unequal distribution of income is the consequence of historical, political, cultural and economic processes. These processes influence the availability of private resources to individuals and determine the nature of public infrastructure for health care services, food availability, education, transport, control of the environment, quality of housing and rules and regulations in the workplace.

The neighbourhood environmental effects on health could have important policy implications, given the possibility of designing interventions that could potentially affect the health of entire neighbourhoods.[13] Consequently, the interest in neighbourhood-level SES and deprivation on pregnancy and birth outcomes is increasing.[14-23] A historical analysis of socio-economic inequalities in infant and perinatal mortality from 1954 to 1990 in Amsterdam, for example, shows that absolute differences in infant mortality decreased, but relative differences increased during the study period with deprived areas having relatively high rates compared to non deprived areas.[16] However, information on the effect of neighbourhood-level SES and deprivation on some of the important pregnancy outcomes, such as pregnancy induced hypertension (PIH) is still lacking. In addition, studies of neighbourhood-level SES on pregnancy outcomes have shown inconsistent results.[17-18] For example, Luo et al.[17] found a strong relationship between neighbourhood-level SES (as 
measured by neighbourhood median income) and preterm birth in Canada. Kaufman et al.,[18] however, found no relationship between neighbourhood income and preterm birth in White-Americans in the USA. The effect of neighbourhood-level income on pregnancy outcomes has also been shown to vary between different settings.[14] Furthermore, many studies did not have information on important individual-level factors that have been shown to influence pregnancy and birth outcomes such as ethnicity, maternal SES, smoking and obesity.[24]

These inconsistent results and the lack of data on pertinent pregnancy outcomes such as PIH clearly indicate the need for more studies on this topic especially in Europe where information is very limited.

The main objective of this present paper was therefore to assess the effect of neighbourhood income and unemployment/social security benefit (deprivation) on pregnancy outcomes (preterm delivery, small for gestational age (SGA), PIH and miscarriage/perinatal death) in Amsterdam, the Netherlands. We hypothesised that low neighbourhood income and deprivation would be associated with poor pregnancy outcomes after adjustment for individual-level characteristics.

\section{DATA AND METHODS}

The data for this study came from two different sources. The individual-level data were obtained from the Amsterdam Born Children and their Development (ABCD) study, and the neighbourhood-level data were from Statistics Netherlands.

\section{Data collection at the individual level}

The ABCD study was a community cohort investigation of pregnant women $(n=8266)$ residing in Amsterdam, the Netherlands. The ABCD study (see www.abcd-study.nl) investigated differences in pregnancy outcomes with a focus on maternal lifestyle.[25-26] 
Between January 2003 and March 2004, all pregnant women in Amsterdam were invited to participate at their first antenatal visit (median: 13 weeks; interquartile range: 3 weeks) with their obstetric caregiver. In addition to the routine prenatal care provided, a modular pregnancy questionnaire was distributed via mail 2 weeks later, to be returned in a prepaid envelope. This validated questionnaire was administered in 4 languages via a translator's service, and included information on women's socio-demographic characteristics, lifestyle and obstetric history. A reminder was sent 2 weeks later to women who had not returned the questionnaire. In total, 12,373 women were invited to participate, and 8266 women returned the questionnaire (response rate: 67\%). For those women who gave permission for follow-up, additional data were obtained from the National Perinatal Register. Data on gestational age (based on ultrasound or, if unavailable, onset of most recent menstrual period), and birth weight were obtained from the Youth Health Care Registration of Amsterdam's Municipal Health Service. Multiple births $(\mathrm{n}=131)$ were excluded from the analysis. The study protocol was approved by the medical ethical committees of all Amsterdam hospitals and the Municipal Privacy Protection Committee of Amsterdam. All participating women gave informed written consent.

\section{Individual level variables}

\section{Outcome variables}

Preterm births: preterm birth was defined as gestational age of less than 37 weeks.

Small for gestational age (SGA): SGA was defined as a birth weight below the $10^{\text {th }}$ percentile for gestational age on the basis of gender and parity-specific standards.[27]

Pregnancy induced hypertension (PIH): PIH was based on all women who answered yes to the question 'Did you have hypertension or use blood pressure medication during your pregnancy?' or who had, according to the national obstetric register, a high diastolic blood $(\geq$ $90 \mathrm{mmHg}$ ) pressure during pregnancy (filled out by the health care professionals), or a diagnostic code for eclampsia, preeclampsia or PIH (optional fields). Women with a previous 
hypertension history before pregnancy or before 20 weeks gestational age (i.e. chronic hypertension) were excluded from the analyses.

Miscarriage/foetal and neonatal death (miscarriage/perinatal death): Miscarriage/perinatal death was determined from 4 overlapping sources: (1) the National Midwifery Registry, (2) the National Obstetric Registry, (3) the National Neonatal Registry and (4) self-reporting. Miscarriage was defined as death of the foetus occurring before 22 weeks of gestation. The miscarriage group excludes all those with induced abortion. Foetal death was defined as birth of a foetus weighing at least 500 grams (or, where birth weight was unavailable, of at least 22 weeks gestation), which showed no signs of life, and neonatal death was defined as death of infants under 7 days according to existing standards.

Maternal explanatory variables were derived from women's questionnaire responses: age, parity, ethnicity, educational level (measured as years of education completed after primary school), smoking during pregnancy (yes/no) and pre-pregnancy body mass index (BMI). The $\mathrm{ABCD}$ study has no information on maternal income. Hence, maternal education has been used as a proxy for individual-level socio-economic status. The ethnic groups were classified according to country of birth and/or country of birth of the parents in accordance with the definition of Statistics Netherlands.[28]

\section{Neighbourhood-level variable}

The neighbourhood income data were obtained from the "basic statistics for districts and neighborhoods' registered by Statistics Netherlands. The neighbourhood income was based on the percentage of median income of people aged between 15 and 64 years olds in 2003 for each Amsterdam neighbourhood. The neighbourhood unemployment/social security benefit was based on the percentage of people aged between 15 and 64 years who were unemployed or received social security benefit for each Amsterdam neighbourhood. Nine neighbourhoods had small sample sizes ( $<10$ subjects/neighbourhood) and were therefore excluded from the analyses. Data were analysed for 7883 women from 82 neighbourhoods. The average number 
of participants per neighbourhood was 96, ranging from 12 to 386. In the Netherlands, neighbourhoods are areas with a similar type of buildings, often delineated by natural boundaries. As a result of these natural boundaries, they are a socio-culturally homogeneous group.[29]

\section{Data Analysis}

Individual-level data were linked to neighbourhood-level data via participants' postcodes, creating a multilevel design for data analysis. The data were analysed using multilevel logistic regression. First, models were adjusted for age and parity (i.e., physiological characteristics), and then socio-demographic and lifestyle factors (education, ethnicity, smoking and body mass index) were added to determine independent associations between neighbourhood-level factors and pregnancy outcomes. Maternal socio-economic status, ethnicity, smoking and obesity have all been shown to influence pregnancy and birth outcomes.[24-26,30-31] In addition, we calculated the intraclass correlation (ICC) to estimate the proportion of total variation in pregnancy outcomes that occurred at the neighbourhood level, using the latent variable method.[32] Furthermore, we calculated the median odds ratio (MOR), which has a consistent and intuitive interpretation.[33-34] MOR quantifies cluster variance in terms of odds ratios. It is therefore comparable to the fixed effects odds ratio, which is the most widely used measure of effect for dichotomous outcomes. Statistical analyses were performed using Stata version 9.0 (Stata Corp, College Station, Tex, USA).

\section{RESULTS}

Table 1 shows the characteristics of the study population. Mothers living in low income or deprived neighbourhoods were younger, less educated, and were more likely to smoke, and to be obese than their counterparts living in high income neighbourhoods. Ethnic minority mothers were more likely than Dutch mothers to live in low income or deprived neighbourhoods. 
Table 1: Maternal characteristics by neighbourhood income and unemployment/social security benefit quartiles in Amsterdam

\begin{tabular}{|c|c|c|c|c|c|c|c|c|}
\hline & \multicolumn{4}{|c|}{ Median income } & \multicolumn{4}{|c|}{ Unemployment/social security benefit } \\
\hline & $\begin{array}{l}\text { Q1 (poorest) } \\
(\mathrm{n}=2043)\end{array}$ & $\begin{array}{l}\text { Q2 } \\
(\mathrm{n}=1947)\end{array}$ & $\begin{array}{l}\text { Q3 } \\
(\mathrm{n}=2103)\end{array}$ & $\begin{array}{l}\text { Q4 (richest) } \\
(\mathrm{n}=1790)\end{array}$ & $\begin{array}{l}\text { Q1 (lowest) } \\
(\mathrm{n}=1881)\end{array}$ & $\begin{array}{l}\text { Q2 } \\
(\mathrm{n}=1869)\end{array}$ & $\begin{array}{l}\text { Q3 } \\
(\mathrm{n}=1975)\end{array}$ & $\begin{array}{l}\text { Q4 (highest) } \\
(\mathrm{n}=2158)\end{array}$ \\
\hline \multicolumn{9}{|l|}{ Age (yrs) } \\
\hline$<20$ & 4.8 & 3.5 & 1.0 & 0.4 & 1.0 & 2.4 & 2.5 & 3.8 \\
\hline $20-29$ & 51.6 & 39.9 & 23.3 & 16.6 & 21.1 & 32.6 & 36.2 & 41.5 \\
\hline $30-39$ & 40.5 & 53.2 & 72.7 & 79.4 & 74.5 & 62.0 & 58.5 & 50.9 \\
\hline $40-49$ & 3.1 & 3.4 & 3.1 & 3.5 & 3.4 & 3.0 & 2.8 & 3.8 \\
\hline \multicolumn{9}{|l|}{ Education (yrs) $\dagger$} \\
\hline $0-5$ & 44.5 & 28.4 & 11.4 & 7.3 & 11.4 & 20.8 & 26.0 & 33.0 \\
\hline $6-10$ & 40.1 & 41.3 & 37.5 & 32.9 & 39.0 & 37.5 & 38.3 & 37.5 \\
\hline$>10$ & 15.4 & 30.3 & 51.1 & 59.8 & 49.6 & 41.7 & 35.7 & 29.5 \\
\hline \multicolumn{9}{|l|}{ Ethnicity (\%) } \\
\hline Dutch & 34.7 & 59.3 & 77.0 & 79.1 & 76.7 & 65.5 & 60.8 & 47.7 \\
\hline Suriname & 11.8 & 7.9 & 2.1 & 0.9 & 1.6 & 3.1 & 6.8 & 10.1 \\
\hline Turks & 8.8 & 5.3 & 1.8 & 0.4 & 1.5 & 5.0 & 4.8 & 5.3 \\
\hline Moroccan & 16.4 & 8.4 & 3.2 & 1.2 & 2.7 & 8.7 & 8.5 & 9.6 \\
\hline Other & 28.3 & 19.8 & 15.8 & 18.4 & 17.5 & 17.7 & 19.1 & 27.3 \\
\hline \multicolumn{9}{|l|}{ Parity (\%) } \\
\hline Primiparous & 47.5 & 54.2 & 61.3 & 56.9 & 52.7 & 55.7 & 55.8 & 55.5 \\
\hline Multiparous & 52.5 & 45.8 & 38.7 & 43.1 & 47.3 & 44.3 & 44.2 & 44.5 \\
\hline Current smoking, yes (\%) & 10.6 & 12.2 & 9.6 & 5.2 & 6.9 & 9.7 & 11.4 & 9.9 \\
\hline \multicolumn{9}{|l|}{ Pre-pregnancy BMI } \\
\hline $\mathrm{BMI}<=25 \mathrm{~kg} / \mathrm{m}^{2}$ & 63.6 & 72.2 & 84.3 & 85.4 & 81.4 & 78.0 & 74.9 & 71.6 \\
\hline $\mathrm{BMI}>=25 \mathrm{~kg} / \mathrm{m}^{2}$ & 25.0 & 20.5 & $\begin{array}{l}0+. J \\
12.4\end{array}$ & 11.2 & $\begin{array}{l}01.4 \\
14.5\end{array}$ & 16.5 & 18.3 & 19.9 \\
\hline $\mathrm{BMI}>=30 \mathrm{~kg} / \mathrm{m}^{2}$ & 11.4 & 7.3 & 3.3 & 3.4 & 4.0 & 5.5 & 6.8 & 8.6 \\
\hline
\end{tabular}

†after primary school 
Table 2: Adverse birth outcomes by neighbourhood income and unemployment/social security benefit quartiles in Amsterdam

\begin{tabular}{lllll}
\hline & Preterm births & SGA births & PIH & $\begin{array}{l}\text { Miscarriage/ } \\
\text { perinatal death }\end{array}$ \\
Income quartiles & & & & \\
Q1 (poorest) & 6.8 & 16.6 & 7.7 & 1.2 \\
Q3 & 6.9 & 13.6 & 8.5 & 1.2 \\
Q2 & 5.9 & 11.2 & 9.1 & 0.7 \\
Q4 (richest) & 5.4 & 8.4 & 9.2 & 0.6 \\
P-values for trend & 0.037 & 0.001 & 0.071 & 0.015 \\
Unemployment/SSB quartiles & & & & \\
Q1 (lowest) & 5.8 & 9.8 & 9.6 & 0.5 \\
Q2 & 5.8 & 11.6 & 9.2 & 1.1 \\
Q3 & 6.7 & 12.6 & 8.3 & 1.1 \\
Q4 (highest) & 6.7 & 15.9 & 7.3 & 1.1 \\
P-values for trend & 0.113 & $<0.001$ & 0.005 & 0.073 \\
& & & & \\
\hline
\end{tabular}

SGA, small for gestational age; PIH, pregnancy induces hypertension

Table 2 shows the distribution of the adverse pregnancy outcomes by neighbourhood factors whilst Table 3 shows the associations between neighbourhood factors and pregnancy outcomes. Pregnant women living in low income neighbourhoods were significantly more likely than those living in high income neighbourhoods to have preterm births, SGA births and miscarriage/perinatal deaths. After further adjustment for educational level, ethnicity, smoking and obesity, however, only SGA births differences persisted. Women living in the quartile of neighbourhoods with the highest percentage of people on unemployment/social security benefit were significantly more likely than those living in the quartile with the lowest percentage on unemployment/social security benefit to have SGA births. The difference persisted after further adjustment for educational level, ethnicity, smoking and obesity: odds ratio 1.36 (95\% CI: 108-1.72). Women living in the quartile of neighbourhoods with the highest unemployment/social security benefit were also significantly more likely to have a miscarriage/perinatal death than those living in the quartile with the lowest unemployment/social security benefit. The differences were no longer statistically significant after further adjustment for education, ethnicity, smoking and obesity. There were no 
statistically significant associations between neighbourhood income, unemployment/social security benefit and other adverse birth outcomes.

Only the neighbourhood variation in SGA births (i.e. the random intercept in the empty model) was statistically significant (neighbourhood variance (standard error) was 0.092 (0.028), ICC was 0.022, and median odds ratio was 1.34 (95\% CI: $1.20-1.44)$. The variance between neighbourhoods attenuated but still remained significant after adjustment for all the individual level factors (neighbourhood variance was 0.035 (0.017), ICC was 0.011 and median odds ratio was 1.20 (95\% CI: 1.04-1.28). Further adjustment for neighbourhood-level factors removed the significant variation between neighbourhoods and reduced neighbourhood variance to $0.011(0.015)$. 
Table 3: Odds ratios ( $95 \%$ CI) of adverse birth outcomes and neighbourhood income and unemployment/social security benefit quartiles

\begin{tabular}{|c|c|c|c|c|c|c|c|c|}
\hline & \multicolumn{2}{|l|}{ Preterm births } & \multicolumn{2}{|c|}{ Small for gestation age births } & \multicolumn{2}{|c|}{ Pregnancy induced hypertension } & \multicolumn{2}{|c|}{ Miscarriage/perinatal death } \\
\hline & Model 1 & Model 2 & Model 1 & Model 2 & Model 1 & Model 2 & Model 1 & Model 2 \\
\hline & OR $(95 \% \mathrm{CI})$ & OR $(95 \% \mathrm{CI})$ & OR $(95 \% \mathrm{CI})$ & OR $(95 \% \mathrm{CI})$ & OR $(95 \% \mathrm{CI})$ & OR $(95 \% \mathrm{CI})$ & OR $(95 \% \mathrm{CI})$ & OR $(95 \% \mathrm{CI})$ \\
\hline \multicolumn{9}{|c|}{ Median income } \\
\hline Q4 (richest) & Reference & Reference & Reference & Reference & Reference & Reference & Reference & Reference \\
\hline Q3 & $1.07(0.79,1.44)$ & $1.02(0.78,1.35)$ & $1.40(1.08,1.81)^{* *}$ & $1.32(1.04,1.68)^{*}$ & $1.00(0.74,1.34)$ & $1.00(0.74,1.34)$ & $1.30(0.58,2.96)$ & $1.22(0.55,2.74)$ \\
\hline Q2 & $1.35(1.00,1.81)^{*}$ & $1.12(0.84,1.49)$ & $1.63(1.26,2.11)^{* * *}$ & $1.42(1.11,1.82)^{* *}$ & $1.05(0.77,1.42)$ & $1.04(0.76,1.42)$ & $2.35(1.09,5.07)^{*}$ & $1.81(0.83,3.96)$ \\
\hline Q1 (poorest) & $1.36(1.00,1.85)^{*}$ & $1.03(0.76,1.40)$ & $1.93(1.48,2.50)^{* * *}$ & $1.62(1.25,2.08)^{* * *}$ & $1.04(0.75,1.45)$ & $1.07(0.76,1.51)$ & $2.30(1.05,5.07)^{*}$ & $1.64(0.72,3.74)$ \\
\hline \multicolumn{9}{|c|}{ Unemployment/SSB } \\
\hline Q1 (lowest) & Reference & Reference & Reference & Reference & Reference & Reference & Reference & Reference \\
\hline Q2 & $1.01(0.74,1.36)$ & $0.95(0.74,1.28)$ & $1.15(0.88,1.49)$ & $1.10(0.86,1.39)$ & $0.95(0.72,1.26)$ & $1.00(0.75,1.33)$ & $2.35(1.03,5.39)^{*}$ & $2.04(0.92,4.52)$ \\
\hline Q3 & $1.18(0.88,1.59)$ & $1.04(0.80,1.37)$ & $1.29(0.99,1.68)$ & $1.15(0.91,1.45)$ & $0.86(0.65,1.14)$ & $0.88(0.66,1.18)$ & $2.31(1.01,5.28)^{*}$ & $1.95(0.88,4.33)$ \\
\hline Q4 (highest) & $1.16(0.89,1.55)$ & $0.97(0.84,1.52)$ & $1.49(0.1 .15,1.93)^{* * *}$ & $1.36(1.08,1.72)^{* *}$ & $0.76(0.57,1.01)$ & $0.79(0.59,1.07)$ & $2.28(1.00,5.18)^{*}$ & $1.78(0.80,3.99)$ \\
\hline
\end{tabular}

Model 1 (adjusted for age and parity) model 2 (plus educational level and ethnicity, smoking and BMI); SSB, social security benefit; ${ }^{*} \mathrm{p}<0.05, * * \mathrm{p}<0.01, * * * \mathrm{p}<0.001$ 


\section{DISCUSSION}

\section{Key findings}

The main objective of this paper was to assess the effect of neighbourhood income and deprivation on pregnancy outcomes in Amsterdam, the Netherlands. Our study findings indicate that neighbourhood income and deprivation are related to SGA births. We also observed neighbourhood variation in SGA births, and neighbourhood-level factors contributed to the variation between neighbourhoods. There were no significant associations between neighbourhood income, deprivation and other pregnancy outcomes.

\section{Strengths and limitations}

One of the main strengths of our study is that it included several individual level factors pertinent to birth outcomes as compared to previous studies.[14,17,18,21,23] The current study is also one of the few studies to assess the effect of neighbourhood income and deprivation on several pregnancy outcomes. The neighbourhoods considered in our study were socio-culturally homogeneous communities. It has been emphasised that contextual or area bound factors such as low income may have a greater impact on health if a neighbourhood relates to a socio-culturally homogeneous community.[29] Our study also has limitations. Due to small numbers, we combined miscarriage, foetal and neonatal deaths. Future studies should assess the possible differences in the effect of neighbourhood income and deprivation on each of these outcomes. In addition, the inclusion of the pregnant women occurred during their first prenatal visit, which was on average at $12^{\text {th }}$ (inter quartile range 914) week gestational age. This indicates that we missed women who had their miscarriage before the first visit.

\section{Discussion of the key findings}

Our finding of associations between neighbourhood income, deprivation and SGA births is consistent with a previous study,[14] and supports the importance of the effect of neighbourhood factors on pregnancy outcomes. Socio-economic factors can have profound effects on individuals' health as well as the health of populations, and the perinatal domain is 
particularly prone to such influences.[30] The principal pathways by which SES affects perinatal health include those that operate through lifestyle and behavioural factors such as smoking and obesity.[30]

SGA is often used as a proxy for intra-uterine growth restriction (IUGR).[24,31] IUGR is believed to be related to poor foetal nutrition and/or reduced foetal oxygenation.[35] The mechanism underlying the effect of poor neighbourhoods on SGA is unclear. Neighbourhoodlevel determinants, such as low income or deprivation, are, however, considered as antecedent to individual-level exposures and behaviours,[24] which may increase the risk of poor pregnancy outcomes. For example, it has been shown that poor maternal nutrition especially around the time of conception is associated with an increased risk of SGA births.[36] Pregnant women's dietary choices may be influenced by the availability of food stores and food service places in their neighbourhoods. Neighbourhoods that share socio-economic characteristics also tend to share physical (e.g., pollution and availability of nutritious food), social (e.g., crime and behavioral norms) and service (e.g., transportation and health care) environments and these environments could influence health above and beyond the health effects of the socio-economic characteristics of residents living within them.[37-38] It is therefore possible that pregnant women living in poor or deprived neighbourhoods may have limited access to essential services such as access to healthy food, which may affect foetal nutrition and/or oxygenation, and subsequently increase the risk of SGA. Studies from the USA and the UK, for example, suggest that because of unequal geographical distribution, people with low income have fewer choices and less access to healthy food than their high income counterparts.[39-40]

The associations between neighbourhood income, deprivation and SGA remained after further adjustments for individual-level factors, which suggest that other factors may also play a role. For example, both neighbourhood-level and individual-level psychosocial factors have been shown to be related to an increased risk of SGA births.[41-42] Pregnant women with low SES 
experience more stressful life events during their pregnancy than women with high SES.[43] It has been shown that chronic stressors are embedded within and accrued from the environment of women with low SES.[44] More studies are needed to explore the role of other neighbourhood factors, such as psychosocial stressors [45-46], on pregnancy outcomes.

The neighbourhood median income differences in preterm births and miscarriage/perinatal death disappeared after adjustments for individual-level factors. This finding on miscarriage/ perinatal death is consistent with previous studies.[14,16,17] However, the lack of relationship between neighbourhood income, deprivation and preterm births after adjustments for individual-level factors contrasts other studies.[14,17] The relationship between neighbourhood income, deprivation and preterm births remains inconsistent.[14,17,18,21,23] Canadian studies,[14,17] for example, found a strong relationship between neighbourhood income and preterm births after further adjustment for individual level factors. Some USA studies,[18,21] however, found neighbourhood income to be associated with preterm births but only in African-Americans. One recent study from the USA,[21] by contrast, found weaker associations among African-Americans compared with White-Americans. The explanations for these inconsistent results are unclear. However, differences in study design, neighbourhood context, and the different definitions of neighbourhood deprivation may contribute to these observed differences.

As far as we are aware, this is the first study to assess the effect of neighbourhood-level deprivation on PIH. We found no association between neighbourhood deprivation and PIH. However, there was a significant age and parity adjusted association between neighbourhood median income (i.e. first quartile and fourth quartile) and chronic hypertension 1.41 (95\% CI: $1.00,1.99)$. This suggests that women in deprived neighbourhoods, especially ethnic minority women, might still be at an increased risk of hypertension related problems in pregnancy, despite the lack of differences in PIH. Hypertension is highly prevalent among some ethnic minority women in the Netherlands.[47-48] In the SUNSET study, for example, African- 
Surinamese women were nearly 4 times and Hindustani-Surinamese women were nearly 3

times more likely than Dutch women to be hypertensive.[47]

Our study findings may have public health and clinical implications. SGA infants are more likely to have problems with perinatal asphyxia, and are at increased risk of long-term growth deficits and early infant mortality.[49] They also have an increased long-term risk of developing metabolic and cardiovascular diseases (Barker hypothesis).[50] Prevention of SGA is therefore of clinical and public health importance. Our current findings clearly indicate the need for further studies to unravel the possible mechanism underlying the effect of poor neighbourhood environment on pregnancy outcomes.

In conclusion, our findings suggest that neighbourhood income and deprivation are related to SGA births and that more clinical attention may be needed during pregnancy for women from low income or deprived neighbourhoods. More work is needed to explore possible mechanisms underlying poor neighbourhood environment and pregnancy outcomes. Such information might be necessary to help improve maternal and foetal health. 


\section{What is already known on this subject}

* Neighbourhood in which people live influences their health.

* Information on the effect of neighbourhood-level SES and deprivation on pregnancy. outcomes is limited and inconsistent.

\section{What this paper adds}

* Neighbourhood-level income and deprivation are associated with SGA births but not preterm birth, child loss and PIH in Amsterdam, the Netherlands 


\section{Acknowledgement}

We thank Dr A. de Jonge (TNO, Leiden) for providing useful comments on an earlier draft.

\section{Competing interests}

The authors declare that they have no competing interests.

\section{Funding}

C. Agyemang was supported by a VENI fellowship (grant number 916.76.130) awarded by the Board of the Council for Earth and Life Sciences (ALW) of the Netherlands Organisation for Scientific Research (NWO). 


\section{References}

1. Pickett KE, Pearl M. Multilevel analyses of neighbourhood socioeconomic context and health outcomes: a critical review. J Epidemiol Community Health 2001;55:111-22.

2. van Kamp I, van Loon J, Droomers M et al. Residential environment and health: a review of methodological and conceptual issues. Rev Environ Health 2004;19:381-401.

3. Yen IH, Syme SL. The social environment and health: a discussion of the epidemiologic literature. Annu Rev Public Health 1999;20:287-308.

4. Sampson RJ, Morenoff J, Gannon-Rowley T. Assessing 'neighborhood effects': social processes and new directions in research. Annual Review of Sociology 2002;28:443-478.

5. Ellen IG, Tod M, Keri-Nicole D. Neighborhood effects on health: Exploring the links and assessing the evidence. J Urban Aff 2001;23:391-408.

6. Culhane JF, Elo IT. Neighborhood context and reproductive health. Am J Obstet Gynecol 2005;192(5 Suppl):S22-S29.

7. Jessop EG. Individual morbidity and neighbourhood deprivation in a non-metropolitan area. J Epidemiol Community Health 1992;46:543-546.

8. Smith GD, Hart C, Blane D, Gillis C, Hawthorne V. Lifetime socioeconomic position and mortality: prospective observational study. BMJ 1997;314:547-552.

9. Humphreys K, Carr-Hill R. Area variations in health outcomes: artefact or ecology. Intern J Epidemiolog 1991;20:251-258.

10. Lynch J, Davey Smith G, Kaplan G et al. Income inequality and mortality: Importance to health of individual income, psychosocial environment or material conditions. BMJ 2000;320:1200-04.

11. Lynch J, Davey Smith G, Harper S et al. Is Income Inequality a Determinant of Population Health? Part 1. A Systematic Review. Milbank Q 2004;82:5-99.

12. Muntaner C, Lynch J, Hillemeier M et al. Economic inequality, working-class power, social capital, and cause-specific mortality in wealthy countries. Int J Health Serv 2002;32:423-32. 
13. Cubbin C, Marchi K, Lin M et al. Is neighborhood deprivation independently associated with maternal and infant health? Evidence from Florida and Washington. Matern Child Health J. 2008;12:61-74.

14. Zhong-Cheng L, Wilkins R, Kramer MS. Effect of neighborhood income and maternal education on birth outcomes: a population-based study. CMAJ 2006;174:1415-20.

15. Pickett KE, Collins J, Masi CM et al. The effects of racial density and income incongruity on pregnancy outcomes. Soc Sci Med 2005;60:2229-38.

16. van de Mheen H, Reijneveld SA. Mackenbach JP. Socioeconomic inequalities in perinatal and infant mortality from 1854 to 1990 in Amsterdam, the Netherlands. Eur J Public Health. 1996;6:166-174.

17. Luo ZC, Kierans WJ, Wilkins R et al. Disparities in birth outcomes by neighborhood income: temporal trends in rural and urban areas, British Columbia. Epidemiology 2004;15:679-86.

18. Kaufman JS, Dole N, Savitz DA et al. Modeling community level effects on preterm birth. Ann Epidemiol 2003;13:377-84.

19. Ahern J, Pickett KE, Selvin S et al. Preterm birth among African American and white women: a multilevel analysis of socioeconomic characteristics and cigarette smoking. $J$ Epidemiol Community Health 2003;57:606-11.

20. O'Campo P, Xue X, Wang MC et al. Neighborhood risk factors for low birthweight in Baltimore: a multilevel analysis. Am J Public Health 1997;87:1113-18.

21. Pickett KE, Ahern JE, Selvin S et al. Neighborhood socioeconomic status, maternal race and preterm delivery: a casecontrol study. Ann Epidemiol 2002;12:410-18.

22. Rauh VA, Andrews HF, Garfinkel RS. The contribution of maternal age to racial disparities in birthweight: a multilevel perspective. Am J Public Health 2001;91:1815-24.

23. O'Campo P, Burke JG, Culhane J et al. Neighborhood deprivation and preterm birth among non-Hispanic Black and White women in eight geographic areas in the United States. Am J Epidemiol. 2008;167:155-63. 
24. Kramer MS. Determinants of low birth weight: methodological assessment and metaanalysis. Bull World Health Organ 1987;65:663-737.

25. Alderliesten ME, Vrijkotte TG, van der Wal MF et al. Late start of antenatal care among ethnic minorities in a large cohort of pregnant women. BJOG 2007;114:1232-9.

26. Goedhart G, van Eijsden M, van der Wal MF, Bonsel GJ. Ethnic differences in preterm birth and its subtypes: the effect of a cumulative risk profile. BJOG 2008;115:710-9.

27. The Netherlands Perinatal Registry. Perinatal care in The Netherlands 2001 (in Dutch: Perinatale zorg in Nederland 2001). Personal communication Prof.dr. G.J. Bonsel

28. Central Bureau of Statistics. Standaarddefinitie van allochtonen. Index, No. 10, CBS, 2000:10-13.

29. Reijneveld SA, Verheij RA, Bakker DH. The impact of area deprivation on differences in health: Does the choice of the geographical classification matter? J Epidemiol Community Health 2000;54:306-13.

30. Joseph KS, Liston RM, Dodds L et al. Socioeconomic status and perinatal outcomes in a setting with universal access to essential health care services. CMAJ 2007;177:583-90.

31. Kramer MS, Séguin L, Lydon J et al. Socio-economic disparities in pregnancy outcome: why do the poor fare so poorly? Paediatr Perinat Epidemiol 2000;14:194-210.

32. Snijders TAB, Bosker RJ. Multilevel analysis: an introduction to basic and advanced multilevel modeling. Thousand Oaks, CA: Sage, 1999.

33. Larsen K, Merlo J. Appropriate assessment of neighborhood effects on individual health—integrating random and fixed effects in multilevel logistic regression. Am J Epidemiol 2005;161:81-8.

34. Larsen K, Petersen JH, Budtz-Jorgensen E et al. Interpreting parameters in the logistic regression model with random effects. Biometrics 2000;56:909-14.

35. Ergaz Z, Avgil M, Ornoy A. Intrauterine growth restriction-etiology and consequences: what do we know about the human situation and experimental animal models? Reprod Toxicol. 2005;20:301-22. 
36. Mitchell EA, Robinson E, Clark PM et al. Maternal nutritional risk factors for small for gestational age babies in a developed country: a case-control study. Arch Dis Child Fetal Neonatal Ed. 2004;89:431-5.

37. Macintyre S, Ellaway A, Cummins S. Place effects on health: How can we conceptualise, operationalise and measure them? Soc Sci Med 2002;55:125-139.

38. Jessop EG. Individual morbidity and neighbourhood deprivation in a non-metropolitan area. J Epidemiol Community Health 1992;46:543-546.

39. Ellaway A, Macintyre S. Shopping for food in socially contrasting localities. British Food Journal 2000;102:52-59.

40. Morland K, Wing S, Diez Roux A et al. Neighborhood characteristics associated with the location of food stores and food service places. Am J Prev Med. 2002;22:23-9.

41. Masi CM, Hawkley LC, Piotrowski ZH et al. Neighborhood economic disadvantage, violent crime, group density, and pregnancy outcomes in a diverse, urban population. Soc Sci Med. 2007;65:2440-57.

42. Dejin-Karlsson E, Hanson BS, O'stergren PO et al. Association of a lack of psychosocial resources and the risk of giving birth to small for gestational age infants: a stress hypothesis. BJOG 2000;107:89-100.

43. Rutter DR, Quine L. Inequalities in pregnancy outcome: a review of psychosocial and behavioural mediators. Soc Sci Med 1990;30:553-568.

44. Séguin L, Potvin L, Loiselle J et al. Chronic stressors, social support, and depression during pregnancy. Obstet Gynecol. 1995;85:583 589.

45. Agyemang C, van Hooijdonk C, Wendel-Vos W et al. Ethnic differences in the effect of environmental stressors on blood pressure and hypertension in the Netherlands. $B M C$ Public Health. 2007;7:118.

46. Agyemang C, van Hooijdonk C, Wendel-Vos W et al. The association of neighbourhood psychosocial stressors and self-rated health in Amsterdam, The Netherlands. J Epidemiol Community Health. 2007;61:1042-9. 
47. Agyemang C, Bindraban N, Mairuhu G, Montfrans G, Koopmans R, Stronks K.

Prevalence, awareness, treatment, and control of hypertension among Black Surinamese, South Asian Surinamese and White Dutch in Amsterdam, The Netherlands: the SUNSET study. J Hypertens 2005;23:1971-7.

48. Agyemang C, van Valkengoed I, van den Born BJ, Stronks K. Prevalence and determinants of prehypertension among African Surinamese, Hindustani Surinamese, and White Dutch in Amsterdam, the Netherlands: the SUNSET study. Eur J Cardiovasc Prev Rehabil. 2007;14:775-81.

49. Yanney M, Marlow N. Paediatric consequences of fetal growth restriction. Semin Fetal Neonatal Med. 2004;9:411-8.

50. Osmond C, Barker DJ. Fetal, infant, and childhood growth are predictors of coronary heart disease, diabetes, and hypertension in adult men and women. Environ Health Perspect. 2000;108 (Suppl 3):P545-P553. 